\title{
Problematic mobile phone use in adolescents: derivation of a short scale MPPUS-10
}

Milena Foerster ${ }^{1,2}$, Katharina Roser ${ }^{1,2}$, Anna Schoeni ${ }^{1,2}$, Martin Röösli ${ }^{1,2}$

${ }^{1}$ Swiss Tropical and Public Health Institute, Basel, Switzerland

${ }^{2}$ University of Basel, Basel, Switzerland

\section{Corresponding author:}

Martin Röösli

Swiss Tropical and Public Health Institute

Socinstrasse 57

P.O. Box

CH-4002 Basel

E-Mailmartin.roosli@unibas.ch

Tel. $\quad+41(0) 612848383$

Fax +41(0)612848501 


\section{Abstract}

\section{Objectives}

Our aim was to derive a short version of the Mobile Phone Problem Use Scale (MPPUS) using data from 412 adolescents of the Swiss HERMES (Health Effects Related to Mobile phonE use in adolescentS) cohort.

\section{Methods}

A German version of the original MPPUS consisting of 27 items was shortened by principal component analysis (PCA) using baseline data collected in 2012. For confirmation the PCA was carried out again with follow-up data one year later.

\section{Results}

PCA revealed four factors related to symptoms of addiction(“Loss of Control”, "Withdrawal”, "Negative Life Consequences" and "Craving") and a fifth factor reflecting the social component of mobile phone use ("Peer Dependence"). The shortened scale (MPPUS-10) highly reflects the original MPPUS (Kendalls' Tau: 0.80 with $90 \%$ concordant pairs). Internal consistency of MPPUS-10 was good with Cronbach's alpha: 0.85 . The results were confirmed using the follow-up data.

\section{Conclusions}

The MPPUS-10 is a suitable instrument for research in adolescents. It will help to further clarify the definition of problematic mobile phone use in adolescents and explore similarities and differences to other technological addictions.

\section{Key words}

Mobile phone use, Problematic mobile phone use, MPPUS, Technological addictions, Adolescents 


\section{Introduction}

Since the mid-nineties and the public availability of the internet and mobile phones, the use of electronic media devices rapidly increased. According to the International

Telecommunication Union (ITU) the amount of mobile phone subscriptions has grown from 2.2 billion in 2005 to 6.9 billion in 2014 (ITU 2014). Despite the facilitating effects of mobile phones like the ease of accessibility or useful applications, for example in health care (Boulos et al. 2011), concerns about adverse effects on social communication patterns and health due to new information technologies have arisen (Kowall et al. 2012; Schreier et al. 2006; Srivastava 2005). In 2014, $98 \%$ of adolescents own a mobile phone in Switzerland (thereof 97\% a smartphone) (Willemse et al. 2014). Problematic mobile phone use (also known as mobile phone addiction, compulsive mobile phone use) has been documented for adolescents and young adults, whereby affected persons experience unpleasant symptoms of withdrawal when switching off their mobile phone or being out of range (Campbell 2005; Walsh et al. 2007). In addition, a variety of adverse health effects such as depression, social anxiety, insomnia, hyperactivity or conduct problems have been associated with different forms of technology-overuse (Canan 2013; Cheung and Wong 2011; Jenaro et al. 2007; Morgan and Cotten 2003; Thomée et al. 2011). Behavioural addictions are like drug addictions characterized through maintaining abuse despite of its adverse consequences. While in drug addictions short term rewards, so-called highs, are gained from and necessarily need chemical substance-intake, in behavioural addictions similar effects, neurologically and emotionally, are reached through engaging in specific behaviours (Clark and Limbrick-Oldfield 2013). The primary diagnostic symptoms of substance abuse include withdrawal, loss of control, tolerance or craving and are featured by behavioural addictions as well. Those symptoms cause major negative life consequences in the affected person like impaired health or deprived social functioning (Park 2005). 
One major problem in research on problematic mobile phone use is the inconsistency in its definition and assessment. Bianchi and Phillips have introduced a 27-item Mobile Phone Problem Use Scale (in the following referred to as MPPUS-27)which addresses different aspects of addiction (Bianchi and Phillips 2005). Particularly, the aspects of Tolerance, Escape from other problems, Withdrawal, Craving and Negative Life Consequences are emphasized by the authors. The MPPUS-27 is frequently used in research on problematic mobile phone use (Izdebski and Kotyśko 2013; Lopez-Fernandez et al. 2014; LopezFernandez et al. 2011; Richardson 2012). The scale shows excellent internal consistency (Cronbach`s $\alpha>0.9$ ) and is validated in an adult sample through comparison with general mobile phone usage behaviour and the Addiction Potential Scale (APS) of the Minnesota Multiphasic Personality Inventory (MMPI-2). Despite of those strengths it is long and tends to be somewhat redundant which may be a problem for research in adolescents. This may elevate the risk to upset the study participants and may lead to blindfold answers on similar items. Further, it has not yet been evaluated in adolescent research. For that reason we aimed at developing a short MPPUS suitable for adolescents by using data from the ongoing HERMES (Health Effects Related to Mobile phonE use in adolescentS) study.

\section{Methods}

\section{Study population}

The HERMES study aims to investigate effects of mobile phone use on health and behaviour of adolescents. The study population consists of $7^{\text {th }}, 8^{\text {th }}$ and $9^{\text {th }}$ grade students (12-17 years) attending secondary schools in Central Switzerland. The baseline investigation took place from June 2012 until March 2013 and each school was visited one year later for a follow-up investigation with the same study participants. Participating adolescents were recruited through initial phone contact with the head of the school and a subsequent informational visit 
in the respective classes. Participation was voluntary and had to be preceded by informed consent of the adolescents and a parent. The investigation took place in school during school time and was led by two study managers. It consisted of filling in a paper and pencil questionnaire on various aspects such as mobile phone use, behavioural aspects, health related quality of life, socio-economic factors and other covariates. Student's mobile phone use was assessed through questionnaire including questions about frequency and duration of calls, frequency of outgoing text messages (text messages sent by mobile phone network referred as SMS as well as other text messages sent by internet based applications like WhatsApp), duration of data traffic on the mobile phone and about the usage of the mobile phone for other purposes. Objective mobile phone use traffic data was provided from the three mobile phone operators in Switzerland for the participants who gave informed consent together with their parents to collect these data. These operator data included the amount of outgoing and incoming calls and SMS, the duration of calls and the amount and the volume of data traffic sessions for up to six months prior to the investigation. Only participants reporting to own a mobile phone were included in analysis.

Ethical approval for the conduct of the study was received from the ethical committee of Lucerne, Switzerland on May 9, 2012.

\section{Mobile Phone Problem Use Scale (MPPUS)}

The MPPUS-27 consists of 27 items covering the addictive symptoms Tolerance, Escape from other problems, Withdrawal, Craving and Negative Life Consequences s (Bianchi and Phillips 2005) (see table 1). The 27 items have to be answered on a 10-point Likert scale ranging from 1 ("not true at all") to 10 ("extremely true") resulting in a final sum score with a theoretical maximum range of 27 - 270 points. The English version was translated into German by the study managers using a back translation procedure. 
Table one about here

\section{Statistical analysis}

\section{Principal Component Analysis}

We applied principal component analysis (PCA) to derive a short version of the MPPUS for adolescents. The PCA was conducted with data from participants that had no missing in the MPPUS-27 (35 participants $(8.5 \%)$ with at least one missing value; $\mathrm{n}=377$ ). Prior to the analysis we tested the data to be suitable assessing the Kaiser-Meyer-Olkin measure and Bartlett's test for sphericity. Furthermore, an item analysis of the MPPUS-27 items was executed including item-test correlations, item-rest correlations and average inter-item correlations. Additionally the mean and the standard deviation of each item were calculated to evaluate the discriminatory power of the items. Based on those results the less conservative Kaiser-Criterion was chosen for factor extraction which allows factors with eigenvalues above one to be included. Varimax rotation was used to maximize factor loadings. The number of items per factor included in the shortened questionnaire was decided based on the explained variance of each factor. A main criterion for choosing a specific item was its load on the corresponding factor. Further, we preferred items which tend to have stronger discriminatory power. And additionally, we wanted items with face validity for adolescents. Since this cannot be guaranteed by looking at the factor loadings and item-analysis only, we did the final item selection manually. PCA was executed again with the follow-up data one year later.

\section{Missing Items}

To do all further reliability analyses and comparisons with the full sample, missing items of the MPPUS-10 were imputed using a linear regression imputation taking into account the remaining items of the MPPUS-10. From the 35 participants with missing values in the MPPUS-27 only 13 participants had at least one to maximum four missing values in the 
MPPUS-10 items. The same computations were executed with the follow-up data one year later (10 participants with one missing item each in the follow-up MPPUS-10 score).

\section{Reliability measures}

To test the internal consistency of the questionnaire, Cronbach's alpha was assessed for the derived shortened MPPUS scale (referred to as MPPUS-10) as well as for the MPPUS-27. The retest-reliability for the MPPUS-10 between the baseline and follow-up measures was calculated using Pearson's correlation for continual variables.

\section{MPPUS-27 vs. MPPUS-10 relations}

To investigate how well the sum-score of the MPPUS-10 reflects the original score, the Pearson's correlation between the MPPUS-27 and the MPPUS-10 was calculated. Since this approach overestimates the correlation because the MPPUS-10 score is part of the MPPUS-27 score, we also calculated the correlation between the MPPUS-10 and the 17 remaining items of the MPPUS-27. This shows to what extent the 10 final items are reflected by the remaining 17 items only. In addition, to test the concordance of both scales Kendall's Tau was calculated. The proportion of persons assigned to the same rank amongst all participants according to both questionnaire scores was obtained by the following formula:

Percentage of concordant pairs $=0.5 *(\tau+1) * 100$.

\section{Subjective and objective mobile phone use data}

Pearson's correlations were calculated for the MPPUS-10 versus subjectively (questionnaire data) and objectively recorded (operator data) quantitative mobile phone use data including frequency of calls per day, outgoing text messages/SMS per day and daily duration of internet use/ data traffic volume.

Statistical analyses were carried out using STATA version 12.1 (StataCorp, College Station, TX, USA). 


\section{Results}

In total, 439 adolescents participated in the baseline investigation of the HERMES study.

Thereof, $27(6.2 \%)$ reported not to own a mobile phone and were therefore excluded from the data analysis. Thus, data from 412 (93.8) participants owning a mobile phone were included in the baseline data analysis. Of the mobile phone users $315(76.5 \%)$ were smartphone users. $253(61.4 \%)$ of the 412 participants were female and $159(38.6 \%)$ male with a mean age of 14.0 years $(\min =12.1$ years, $\max =17.0$ years $)$. A majority $(67.6 \%)$ were $8^{\text {th }}$ grade students and 317 participants $(76.9 \%)$ went to secondary school, 95 participants $(23.1 \%)$ attended schools of higher education. $79.6 \%$ of the participants were Swiss.

The study participants reported to use their mobile phone on average for 1.3 calls (standard deviation: 1.5 ; maximum: 8.6 ) and for 44.9 min of data traffic (SD: 41.4; 103.6) per day. 151 participants $(36.7 \%)$ reported to send up to 5 messages per day, $50(12.1 \%) 6$ - 15 messages per day, $90(21.8 \%) 16$ - 40 messages per day and 121 participants $(29.4 \%)$ reported to send more than 40 messages per day. According to objectively recorded operator data available from 234 (56.8\%) participants they used their mobile phone for 0.8 calls (SD: 1.7 ; maximum: 8.5), sending 2.8 short text messages (SMS) (SD: 5.0; 40.2) per day and the daily data traffic volume exchanged was $3.9 \mathrm{MB}(\mathrm{SD}: 9.3 ; 50.5)$. Note that operator data include only messages sent by short message services (SMS) but not by internet based applications, whereas self-reported messages refer to both type of messages.

\section{Principal component analysis}

PCA was performed using complete MPPUS-27 questionnaires of 377 (91.5\%) participants. Because test scores were left skewed data was z-standardized prior to analysis. In order to test the data to be suitable for PCA we assessed the Kaiser-Meyer-Olkin (KMO) measure of sampling adequacy which was 0.909 (rejection if $\mathrm{KMO}<0.5$ ). We tested the data for 
multicollinearity using Bartlett's test for sphericity which tests the null hypothesis if the correlation matrix is an identity-matrix. With suitable data this test should be significant and we obtained chi $=4317.3, \mathrm{df}=351 ; \mathrm{p}<0.001$. The PCA revealed five factors with eigenvalues above one (see Table 2). Factor interpretation was based on the clinical diagnostic symptoms of addiction and the theoretical considerations of the authors of the MPPUS-27 (Bianchi and Phillips 2005). The factors extracted were named Loss of Control (explanation of $15.9 \%$ of total variance), Withdrawal (12.5\%), Negative Life Consequences (11.8\%), Craving (8.8\%) and Peer Dependence (7.1\%). After factor rotation the five factors explained $56.1 \%$ of the total variance. Although the eigenvalues of factor 4 (subsequently named Craving) and factor 5 (Peer Dependence) were close to one we decided to keep them as single factors because our major consideration was to keep as much content as possible of the original MPPUS.

Eigenvalues, the proportion of explained variance as well as the cumulative proportion of explained variance of the factors are displayed in Table 2.

Table 2 about here

\section{Item selection}

The higher the variance explained by a factor the more items were included in the MPPUS10. Three items loading on the factors Loss of Control and Withdrawal and two from the factor Negative Life Consequences were chosen respectively. One single item was chosen loading on the factors Craving and Peer Dependence since the variance explained by these factors and their eigenvalues were considerably lower compared to the others (see Table 3).

Table 3 about here

We preferred items with a mean value close to the average of the item scores with additionally high standard deviations since they tend to have stronger discriminatory power (see Table 4). 
Table 4 about here

After all we wanted items to be suitable for adolescents thus to be short, easy to understand, unambiguous and non-redundant in their content. Thus, despite high factor load item 11, item 15, item 23 and item 26 were not considered for the factors Craving, Negative Life Consequences, Withdrawal and Peer Dependence respectively. The final short version MPPUS-10 with the chosen items is displayed in Table 5.

Table 5 about here

The PCA was executed again with the follow-up data including data from 378 adolescents owning a mobile phone and filled in all MPPUS-27 items at follow-up to replicate the extracted five factor structure found through the PCA with the baseline data. The analysis with the follow-up data (Table 6) did not noticeably differ from the baseline analysis (Table 3).

Table 6 about here

\section{Reliability of the MPPUS-10}

The mean of the MPPUS-27 was $\mathrm{m}=80.5(\mathrm{SD}: 34.5 ; \min =32, \max =239)$ with a theoretical achievable maximum range of 27 to 270 . The MPPUS-10 had a mean of $\mathrm{m}=28.2$ (SD: 15.6; $\min =10, \max =96)$ with a theoretic maximum range of 10 to 100. Cronbach's alpha measuring the internal consistence was good with alpha $=0.85$ for the MPPUS-10 (Nunnally et al. 1967). In our adolescent sample for the MPPUS-27 alpha was 0.92 which is similar to the internal consistency assessed by Bianchi et al. in an adult sample (0.93). The retest reliability of the MPPUS-10 after one year assessed through Pearson's correlation between baseline and follow-up data was relatively low $(\mathrm{r}=0.40, \mathrm{p}<0.001)$. 


\section{MPPUS-27 vs. MPPUS-10 relations}

The Pearson's correlation between the MPPUS-10 and the MPPUS-27 was $r=0.95, p<0.001$

(Figure 1) and the Pearson's correlation between the MPPUS-10 and the remaining 17 items of the MPPUS-27 was $r=0.86, p<0.001$. Assuming that the first measure overestimates the correlation and the second should rather underestimate it, the true correlation is still quite high. Kendall's Tau for the MPPUS-10 vs. MPPUS-27 was $0.80, \mathrm{p}<0.001$ with a corresponding proportion of concordant ranks among the participants of $90 \%$.

Figure 1 about here

\section{MPPUS-10 vs. quantitative mobile phone use}

The Pearson's correlation between the MPPUS-10 and the self-reported frequency of phone calls was $r=0.31(p<0.001)$. The correlation of the MPPUS-10 with self-reported number of outgoing messages was $r=0.53(p<0.001)$ and for self- reported duration of mobile internet use we found $r=0.41(p<0.001)$. For objectively recorded operator data the Pearson's correlation with the MPPUS-10 score was $r=0.30(p<0.001)$ for phone calls, $r=0.34(p<$ $0.001)$ for frequency of SMS and $r=0.42(p<0.001)$ for the data traffic volume.

\section{Discussion}

The derived short scale using 10 items to measure problematic mobile phone use among adolescents showed a good internal consistency and was highly correlated with the original 27 items scale. A large majority of $90 \%$ of participants had the same rank measured by both scores.

\section{Assessment of problematic mobile phone use}

The assessment and definition of problematic mobile phone use differs in studies on this topic resulting in inconsistency in prevalence rates and cut-off scores. In an Italian study using the 
Mobile Addiction Test (MAT) 6.3\% of adolescents were classified as dependent from their mobile phones (Martinotti et al. 2011). In another study on British adolescents using the MPPUS the $90^{\text {th }}$ percentile was chosen to classify at risk-use according to a statistical classification they prompted to have found in pathological gambling assessment (LopezFernandez et al. 2014). High prevalence rates of about $30 \%$ were reported in studies assessing addictive behaviour through a single questionnaire item ("perceived dependence") (Billieux et al. 2007) or through choosing the $70^{\text {th }}$ percentile as arbitrary questionnaire cut-off value (Ha et al. 2008). In our study we did not find an obvious threshold for differentiating between problematic and non-problematic mobile phone use, which supports the idea that problematic mobile phone use is a continuum and the higher the score on the MPPUS-10, the more likely mobile phone use is problematic in adolescent. A linear association without a threshold for detrimental effects is also supported by our analysis on behavioural and personal factors as well as health symptoms in relation to problematic mobile phone use as measured by the MPPUS-10 (Roser et al. manuscript in preparation).

\section{Problematic mobile phone use in the context of behavioural addictions}

The PCA of the MPPUS revealed five factors. In line with the theoretical construction of the MPPUS, four of them were strongly related to addiction theory and thus were named Loss of Control, Withdrawal, Negative Life Consequences and Craving. The factors show considerable overlap with the symptoms that have been proposed from the authors of the original MPPUS-27 (including also Withdrawal, Negative Life Consequences and Craving). Loss of control, which was described as Tolerance by Bianchi and Phillips (Bianchi and Phillips 2005), deals with the growing time spent with the mobile phone even if not intended. The importance of this factor is also displayed in the correlation between the MPPUS score and quantitative mobile phone use. Withdrawal refers to the mental occupation with the device, i.e. anxious or stressful feelings if being out of range. Negative Life Consequences due 
to a mobile phone might either directly result from the first and second factor or may be due to financial, occupational or school issues. Craving gets obvious if one needs his mobile phone to relief himself from negative feelings. As a fifth factor Peer Dependence was identified. This factor was not described by the authors of the original MPPUS-27. Although peer dependence is not a primary symptom of addictive behaviour it might be important in the development of problematic mobile phone use in adolescents since the mobile phone is mostly used for social communication purposes and peer influence is particularly prevalent in adolescent years (Steinberg and Monahan 2007; Steinberg and Silverberg 1986).

Although these symptoms suit the concept of behavioural addictions, it is important to critically reflect, if problematic mobile phone use may be considered a nosological entity. Whereas few years ago mobile phones were solely used for calling and somewhat later for texting, nowadays with the rapid spreading of smartphones the boundaries between problematic mobile phone use and other technological addictions get blurred due to the various purposes a smartphone may be used for. Problematic mobile phone use may thus involve a combination of various known reinforcing mechanisms of technological addictions such as Online-Gaming Disorder(OGD) and Internet-Addiction (IA).

In online gaming reinforcement is gained through in-game rewards and the ease to escape daily life (Hilgard et al. 2013) and similarly a prominent motive for excessive internet use is diversion (Song et al. 2004). Both, gaming and surfing the web is possible with smartphone use and in our study a higher MPPUS-10 score is correlated with more time spend online and a higher amount of data traffic via mobile phone. Using various applications as well as the perceived satisfaction involved was found to predict compulsive smartphone use (Park and Lee 2011; Salehan and Negahban 2013) and leisure boredom as well as sensation seeking were found as motives in adolescents with higher addictive mobile phone use tendencies 
(Leung 2008). Distraction through technology may be a mechanism which is common for compulsive gaming, surfing or smartphone use.

A different and more distinct motive for problematic mobile phone use might be the need for social communication, which in our results is underlined by the high quantity of outgoing text messages per day and the highest correlations of the MPPUS-10 with this kind of selfreported mobile phone use ( 0.53 vs. $\leq 0.41$ for calling and data exchange). Peer influence, social relationships and the need for belongingness are important factors in adolescents life and to interconnect via mobile phones helps adolescents to satisfy their needs (Gardner and Steinberg 2005; Walsh et al. 2009). The urge to be accessible all the time and feelings of fear and loneliness, if they are out of range have been reported by adolescent heavy users being asked about their mobile phones(Campbell 2005). Studies focussing on personality and emotional impact factors on problematic mobile phone use (messaging and phone calls) emphasize high feelings of loneliness, low self-esteem as well as extraversion being prevalent in high-users (Augner and Hacker 2012; Butt and Phillips 2008; Reid and Reid 2007; Roser et al. manuscript in preparation).

Thus, we suggest two different patterns of problematic mobile phone use. One relates to media entertainment which a few years before required being at home. Nowadays smartphones enable a person to surf the internet and playing online-games everywhere and the use of various applications provides even more possibilities of distraction. This form of problematic mobile phone use may be rather seen as media addiction with the portable smartphone providing the highest accessibility to entertainment. The other form of problematic mobile phone use emphasizes the need for social interconnectivity and relates to the mobile phone used as a communication device. Since the underlying motives and personality factors leading to both forms of problematic mobile phone use differ, it is thinkable that they also lead to distinct health effects. 


\section{Strengths and limitations}

A particular strength of the HERMES study is the objective data on quantitative mobile phone use provided by the Swiss network operators that minimizes recall bias and allows a more robust evaluation between MPPUS-10 and actual mobile phone use. As a limitation we did not have data from a second independent sample and we did not perform a confirmatory factor analysis with the MPPUS-10. However, at least we conducted the PCA again with the follow-up data to replicate its factorial structure. Of note, the relatively low retest coefficient $(\mathrm{r}=0.40)$ may indicate that problematic mobile phone use is not a stable attribute in adolescence, at least during the years of uptake of mobile phone use. The test-retest period of one year is long considering the developmental changes which study participants might have undergone in this timespan. Furthermore, a part of the mobile phone users (17.7\%) in our sample switched to using smartphones during this period, which has a major impact on the usage pattern.

Another limitation is that the MPPUS-10 score was calculated after PCA by summing up the 10 corresponding items of the MPPUS-27. That means, in our study the MPPUS-10 was an artificial questionnaire that was not filled in by the participants. This procedure might have led to overestimations in correlations between the MPPUS-10 and MPPUS-27. To deal with this shortcoming the MPPUS-10 is currently distributed in a second sample of adolescents.

\section{Conclusion}

The MPPUS-10 showed considerable overlap with the original MPPUS-27. Thus we suggest using the shorter MPPUS-10 in future research. It is clearly more convenient since it consists only of 10 items which saves time and is likely to reduce the number of missing items. Our item selection criteria focussed particularly on creating a questionnaire suitable for research in adolescents, which is important considering the high amount of mobile phone use stated for 
this age group in different studies using different methods for assessment (Ha et al. 2008;

Lopez-Fernandez et al. 2014; Martinotti et al. 2011).

Future research in adolescents should focus on disentangling two different patterns of problematic mobile phone use. On the one hand, a smartphone may be excessively used for personal entertainment, which may be similar to other technological addictions (e.g. internet use). On the other hand, a strong need for social interconnectivity may result in problematic mobile phone use as well.

\section{Acknowledgments}

The HERMES study is funded by the Swiss National Science Foundation (project number 138190). In addition the research leading to these results has received funding from the European Community's Seventh Framework Programme (FP7/2007-2013) under grant agreement no 603794 - the GERONIMO project. Many thanks go to the study participants and their parents for participating in the HERMES study.

\section{References}

Augner C, Hacker GW (2012) Associations between problematic mobile phone use and psychological parameters in young adults. Int J Public Health 57:437-441

Bianchi A, Phillips JG (2005) Psychological predictors of problem mobile phone use. CyberPsychology \& Behavior 8:39-51

Billieux J, Van der Linden M, d'Acremont M, Ceschi G, Zermatten A (2007) Does impulsivity relate to perceived dependence on and actual use of the mobile phone? Applied Cognitive Psychology 21:527-537

Boulos MN, Wheeler S, Tavares C, Jones R (2011) How smartphones are changing the face of mobile and participatory healthcare: an overview, with example from eCAALYX. Biomedical engineering online 10:24

Butt S, Phillips JG (2008) Personality and self reported mobile phone use. Computers in Human Behavior 24:346-360

Campbell MA (2005) The impact of the mobile phone on young people's social life. Paper presented at the Social Change in the 21st Century Conference, Brisbane,

Canan F (2013) The Relationship of Affective Temperament and Emotional-Behavioral Difficulties to Internet Addiction in Turkish Teenagers. ISRN psychiatry 2013 
Cheung LM, Wong WS (2011) The effects of insomnia and internet addiction on depression in Hong Kong Chinese adolescents: an exploratory cross-sectional analysis. Journal of sleep research 20:311-317

Clark L, Limbrick-Oldfield EH (2013) Disordered gambling: a behavioral addiction. Current Opinion in Neurobiology 23:655-659 doi:http://dx.doi.org/10.1016/i.conb.2013.01.004

Gardner M, Steinberg L (2005) Peer influence on risk taking, risk preference, and risky decision making in adolescence and adulthood: an experimental study. Developmental psychology 41:625

Ha JH, Chin B, Park D-H, Ryu S-H, Yu J (2008) Characteristics of excessive cellular phone use in Korean adolescents. CyberPsychology \& Behavior 11:783-784

Hilgard J, Engelhardt CR, Bartholow BD (2013) Individual differences in motives, preferences, and pathology in video games: the gaming attitudes, motives, and experiences scales (GAMES). Frontiers in psychology 4

ITU (2014) The World in 2014: ICT Facts and Figures. International Telecommunication Union, Geneva

Izdebski P, Kotyśko M (2013) Personality variables and depression as determinants of problematic use of mobile phones in Poland. Polish Journal of Applied Psychology 11:111-126

Jenaro C, Flores N, Gómez-Vela M, González-Gil F, Caballo C (2007) Problematic internet and cellphone use: Psychological, behavioral, and health correlates. Addiction research \& theory 15:309-320

Kowall B, Breckenkamp J, Blettner M, Schlehofer B, Schüz J, Berg-Beckhoff G (2012) Determinants and stability over time of perception of health risks related to mobile phone base stations. Int J Public Health 57:735-743

Leung $L$ (2008) Linking psychological attributes to addiction and improper use of the mobile phone among adolescents in Hong Kong. Journal of Children and Media 2:93-113

Lopez-Fernandez O, Honrubia-Serrano L, Freixa-Blanxart M, Gibson W (2014) Prevalence of Problematic Mobile Phone Use in British Adolescents. Cyberpsychology, Behavior, and Social Networking 17:91-98

Lopez-Fernandez O, Honrubia-Serrano M, Freixa-Blanxart M (2011) [Spanish adaptation of the" Mobile Phone Problem Use Scale" for adolescent population]. Adicciones 24:123-130

Martinotti G et al. (2011) Problematic mobile phone use in adolescence: a cross-sectional study. Journal of public health 19:545-551

Morgan C, Cotten SR (2003) The relationship between Internet activities and depressive symptoms in a sample of college freshmen. CyberPsychology \& Behavior 6:133-142

Nunnally JC, Bernstein IH, Berge JMt (1967) Psychometric theory vol 226. McGraw-Hill New York,

Park B-W, Lee KC (2011) The effect of users' characteristics and experiential factors on the compulsive usage of the smartphone. In: Ubiquitous computing and multimedia applications. Springer, pp 438-446

Park WK (2005) Mobile phone addiction. In: Mobile Communications. Springer, pp 253-272

Reid DJ, Reid FJ (2007) Text or talk? Social anxiety, loneliness, and divergent preferences for cell phone use. CyberPsychology \& Behavior 10:424-435

Richardson MH (2012) Increased levels of anxiety revealing characteristics of social phobia elucidated by smartphone use. University of Central Florida Orlando, Florida

Roser K, Schoeni A, Foerster M, Röösli M (manuscript in preparation) Problematic mobile phone use: Associations with personal factors, health and behaviour in Swiss adolescents

Salehan M, Negahban A (2013) Social networking on smartphones: When mobile phones become addictive. Computers in Human Behavior 29:2632-2639

Schreier N, Huss A, Röösli M (2006) The prevalence of symptoms attributed to electromagnetic field exposure: a cross-sectional representative survey in Switzerland. Sozial-und Präventivmedizin 51:202-209

Song I, Larose R, Eastin MS, Lin CA (2004) Internet gratifications and Internet addiction: On the uses and abuses of new media. CyberPsychology \& Behavior 7:384-394 
Srivastava L (2005) Mobile phones and the evolution of social behaviour. Behaviour \& Information Technology 24:111-129

Steinberg L, Monahan KC (2007) Age differences in resistance to peer influence. Developmental psychology 43:1531

Steinberg L, Silverberg SB (1986) The vicissitudes of autonomy in early adolescence. Child development:841-851

Thomée S, Härenstam A, Hagberg M (2011) Mobile phone use and stress, sleep disturbances, and symptoms of depression among young adults-a prospective cohort study. BMC Public Health 11:66

Walsh SP, White KM, Young RM (2007) Young and connected: Psychological influences of mobile phone use amongst Australian youth. In: Goggin G, Hjorth L (eds) Proceedings Mobile Media 2007. University of Sydney, Sydney, pp 125-134

Walsh SP, White KM, Young RM (2009) The phone connection: A qualitative exploration of how belongingness and social identification relate to mobile phone use amongst Australian youth. Journal of Community \& Applied Social Psychology 19:225-240

Willemse I, Suess D, Waller G (2014) JAMES-Studie. Jugend, Aktivität, Medien - Erhebung Schweiz. Factsheet Befunde 2014. Zürcher Hochschule für angewandte Wissenschaft, Zürich 
Table 1: The 27-item Mobile Phone Problem Use Scale (MPPUS-27)

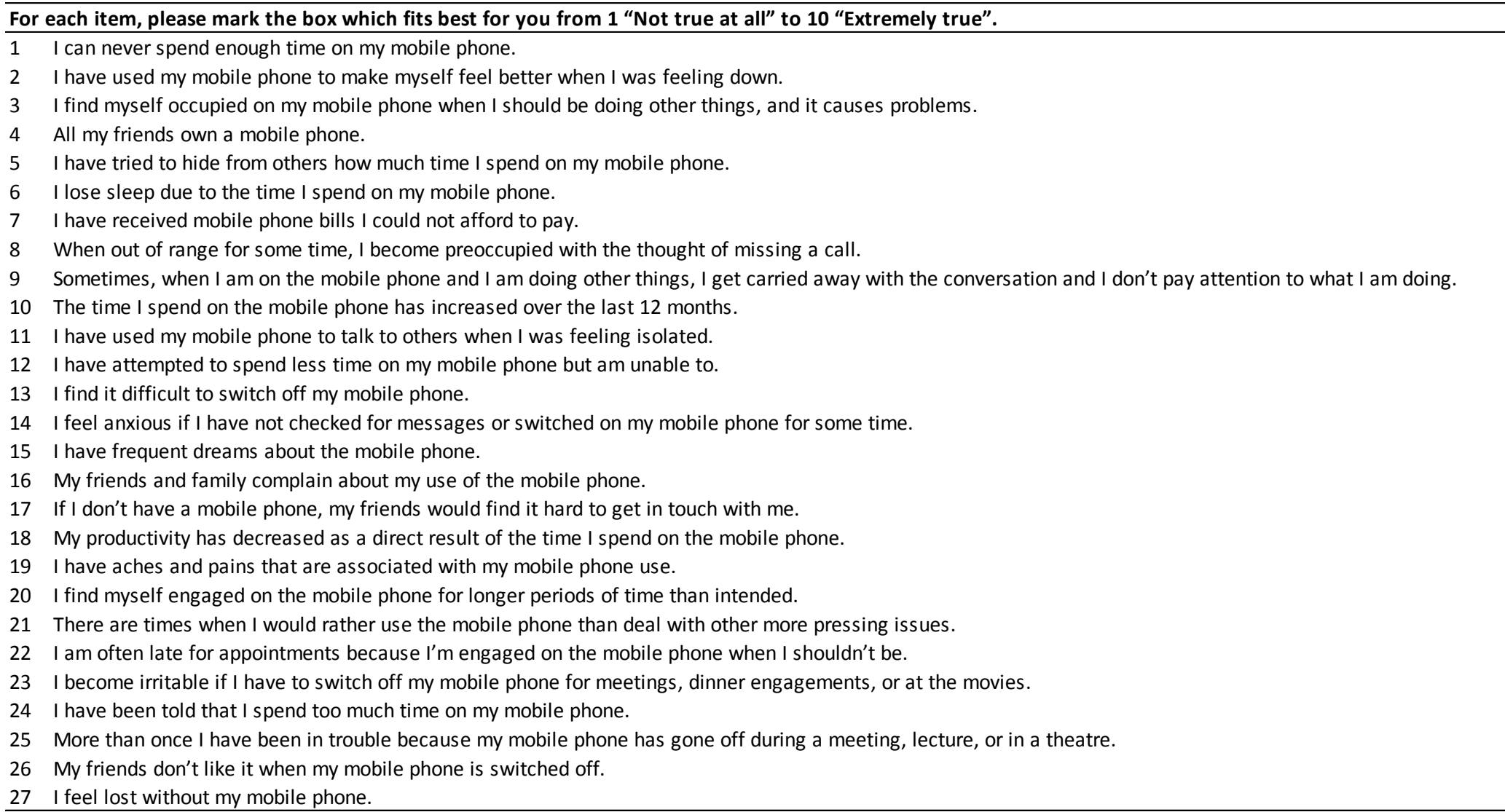


Table 2: Eigenvalues, proportion of explained variance $(\%)$ and the cumulative proportion of explained variance (\%) after factor rotation of the factors. Subsequently chosen names in italic brackets. Factors with eigenvalues below one are omitted.

\begin{tabular}{l|c|c|c}
\hline \multicolumn{1}{c|}{ Factor } & Eigenvalue & $\begin{array}{c}\text { Proportion of } \\
\text { explained } \\
\text { variance (\%) }\end{array}$ & $\begin{array}{c}\text { Cumulative } \\
\text { proportion of } \\
\text { explained variance (\%) }\end{array}$ \\
\hline Factor 1 (subsequently named Loss of Control) & 8.91 & 15.90 & 15.90 \\
Factor 2 (Withdrawal) & 2.38 & 12.47 & 28.37 \\
Factor 3 (Negative Life Consequences) & 1.63 & 11.81 & 40.18 \\
Factor 4 (Craving) & 1.15 & 8.83 & 49.01 \\
Factor 5 (Peer Dependence) & 1.07 & 7.07 & 56.08 \\
\hline
\end{tabular}

Table 3: Factor loadings of the 27 items of the original-Mobile Phone Problem Use Scale (MPPUS-27) on each factor after factor rotation. Item numbers relate to the MPPUS-27 questionnaire displayed in Table 1. The chosen items for the short version Mobile Phone Problem Use Scale-10 (MPPUS-10) are marked in light grey. The factor loadings of the chosen items for the particular factor are marked in bold.

\begin{tabular}{l|c|c|c|c|c}
\hline Factor & Loss of Control & Withdrawal & $\begin{array}{c}\text { Negative Life } \\
\text { Consequences }\end{array}$ & Craving & $\begin{array}{c}\text { Peer } \\
\text { Dependence }\end{array}$ \\
\hline Item & & & & & \\
\hline Item 1 & 0.10 & 0.18 & -0.08 & 0.24 & 0.03 \\
Item 2 & 0.01 & -0.02 & 0.03 & 0.49 & 0.05 \\
Item 3 & 0.26 & 0.05 & -0.01 & 0.07 & 0.10 \\
Item 4 & 0.01 & 0.24 & -0.29 & -0.27 & 0.28 \\
Item 5 & 0.00 & 0.01 & 0.19 & 0.28 & -0.04 \\
Item 6 & 0.16 & 0.09 & 0.02 & 0.21 & -0.09 \\
Item 7 & 0.09 & -0.04 & 0.33 & -0.07 & 0.12 \\
Item 8 & -0.02 & 0.45 & 0.00 & 0.06 & -0.13 \\
Item 9 & 0.10 & 0.33 & 0.01 & -0.08 & -0.03 \\
Item 10 & 0.26 & 0.07 & -0.14 & 0.00 & 0.13 \\
Item 11 & -0.09 & 0.01 & -0.04 & 0.52 & 0.14 \\
Item 12 & 0.26 & 0.07 & 0.08 & 0.07 & -0.07 \\
Item 13 & 0.07 & 0.35 & -0.02 & 0.00 & 0.02 \\
Item 14 & 0.05 & 0.32 & -0.07 & 0.18 & -0.02 \\
Item 15 & -0.16 & 0.10 & 0.43 & 0.00 & 0.02 \\
Item 16 & $\mathbf{0 . 4 8}$ & -0.12 & 0.02 & -0.03 & -0.07 \\
Item 17 & 0.06 & -0.03 & 0.03 & 0.01 & 0.57 \\
Item 18 & 0.13 & -0.10 & 0.27 & 0.07 & 0.12 \\
Item 19 & 0.04 & 0.05 & 0.38 & -0.01 & -0.16 \\
Item 20 & $\mathbf{0 . 3 8}$ & 0.06 & -0.01 & -0.03 & -0.02 \\
Item 21 & 0.27 & 0.07 & -0.01 & -0.01 & 0.10 \\
Item 22 & -0.01 & -0.02 & 0.46 & 0.03 & 0.01 \\
Item 23 & -0.08 & 0.40 & 0.18 & -0.11 & -0.02 \\
Item 24 & $\mathbf{0 . 4 7}$ & -0.12 & 0.06 & -0.03 & -0.09 \\
Item 25 & 0.01 & 0.18 & 0.26 & -0.34 & 0.20 \\
Item 26 & -0.03 & -0.11 & 0.07 & 0.05 & 0.60 \\
Item 27 & -0.05 & 0.28 & -0.01 & 0.17 & 0.18 \\
\hline & & & & \\
\hline
\end{tabular}


Table 4: Number of observations (N), results of item analysis (item-test, item-rest and average inter-item correlation coefficients), means and standard deviations (SD) for each item of the Mobile Phone Problem Use Scale prior to shortening (MPPUS-27). Item numbers relate to the MPPUS-27 displayed in Table 1.

\begin{tabular}{|c|c|c|c|c|c|c|}
\hline & $\mathrm{N}$ & $\begin{array}{c}\text { Item-test } \\
\text { correlation }^{1} \\
\end{array}$ & $\begin{array}{l}\text { Item-rest } \\
\text { correlation }^{2}\end{array}$ & $\begin{array}{c}\text { Average } \\
\text { inter-item correlation }{ }^{3}\end{array}$ & Mean ${ }^{4}$ & $S D^{5}$ \\
\hline Item 1 & 410 & 0.66 & 0.63 & 0.29 & 3.46 & 2.53 \\
\hline Item 2 & 410 & 0.65 & 0.60 & 0.29 & 3.84 & 2.88 \\
\hline Item 3 & 409 & 0.67 & 0.63 & 0.29 & 3.71 & 2.68 \\
\hline Item 4 & 409 & 0.12 & 0.06 & 0.32 & 8.68 & 2.20 \\
\hline Item 5 & 409 & 0.55 & 0.50 & 0.30 & 1.95 & 1.97 \\
\hline Item 6 & 410 & 0.64 & 0.60 & 0.29 & 2.47 & 2.23 \\
\hline Item 7 & 411 & 0.53 & 0.48 & 0.30 & 1.37 & 1.40 \\
\hline Item 8 & 410 & 0.64 & 0.60 & 0.29 & 2.20 & 2.07 \\
\hline Item 9 & 410 & 0.58 & 0.53 & 0.29 & 2.69 & 2.21 \\
\hline Item 10 & 409 & 0.52 & 0.47 & 0.30 & 4.90 & 3.23 \\
\hline Item 11 & 412 & 0.53 & 0.48 & 0.30 & 3.95 & 3.03 \\
\hline Item 12 & 412 & 0.67 & 0.63 & 0.29 & 2.38 & 2.16 \\
\hline Item 13 & 411 & 0.67 & 0.63 & 0.29 & 2.56 & 2.58 \\
\hline Item 14 & 412 & 0.69 & 0.65 & 0.29 & 2.74 & 2.47 \\
\hline Item 15 & 412 & 0.41 & 0.36 & 0.30 & 1.25 & 1.10 \\
\hline Item 16 & 412 & 0.62 & 0.57 & 0.29 & 2.98 & 2.62 \\
\hline Item 17 & 407 & 0.54 & 0.49 & 0.30 & 4.94 & 3.13 \\
\hline Item 18 & 411 & 0.59 & 0.54 & 0.29 & 2.09 & 1.65 \\
\hline Item 19 & 409 & 0.47 & 0.42 & 0.30 & 1.43 & 1.30 \\
\hline Item 20 & 409 & 0.70 & 0.66 & 0.29 & 3.30 & 2.53 \\
\hline Item 21 & 405 & 0.63 & 0.58 & 0.29 & 4.14 & 2.84 \\
\hline Item 22 & 410 & 0.56 & 0.52 & 0.30 & 1.45 & 1.14 \\
\hline Item 23 & 409 & 0.59 & 0.54 & 0.29 & 1.62 & 1.42 \\
\hline Item 24 & 410 & 0.64 & 0.59 & 0.29 & 2.86 & 2.68 \\
\hline Item 25 & 408 & 0.38 & 0.32 & 0.30 & 1.90 & 1.93 \\
\hline Item 26 & 401 & 0.40 & 0.34 & 0.30 & 3.02 & 2.60 \\
\hline Item 27 & 407 & 0.69 & 0.65 & 0.29 & 2.95 & 2.63 \\
\hline Mean & 409 & 0.57 & 0.52 & 0.30 & 2.98 & 2.26 \\
\hline
\end{tabular}

${ }^{1}$ Item-test correlation: correlation between the item score $\mathrm{i}$ and the total test score

${ }^{2}$ Item-rest correlation: correlation between the item score $i$ and the sum of the other item scores excluding item score $\mathrm{i}$

${ }^{3}$ Average inter-item correlation: average of the correlation between the item score $i$ and the other item scores

${ }^{4}$ Mean: mean of the item score $\mathrm{i}$

${ }^{5} \mathrm{SD}$ : standard deviation of the item score $\mathrm{i}$ 
Table 5: The Mobile Phone Problem Use Scale-10 (MPPUS-10) items with the original item number of the original scale, the number of observations $(\mathrm{N})$, factor loadings after rotation, means and standard deviations (SD). Respective factor classification can be found in italic brackets after each item.

\begin{tabular}{|c|c|c|c|c|c|}
\hline Item & Original item & $\mathrm{N}$ & Factor loading & Mean & SD \\
\hline \multicolumn{6}{|l|}{ For each item, please mark the box which fits best for you from 1 "Not true at all" to 10 "Extremely true". } \\
\hline I have used my mobile phone to make myself feel better when I was feeling down. (Craving) & 2 & 410 & 0.49 & 3.84 & 2.89 \\
\hline When out of range for some time, I become preoccupied with the thought of missing a call. (Withdrawal) & 8 & 410 & 0.45 & 2.20 & 2.07 \\
\hline If I don't have a mobile phone, my friends would find it hard to get in touch with me. (Peer acceptance) & 17 & 407 & 0.57 & 4.94 & 3.13 \\
\hline I feel anxious if I have not checked for messages or switched on my mobile phone for some time. (Withdrawal) & 14 & 412 & 0.32 & 2.74 & 2.47 \\
\hline My friends and family complain about my use of the mobile phone. (Loss of control) & 16 & 412 & 0.48 & 2.98 & 2.62 \\
\hline I find myself engaged on the mobile phone for longer periods of time than intended. (Loss of control) & 20 & 409 & 0.38 & 3.30 & 2.53 \\
\hline I am often late for appointments because I'm engaged on the mobile phone when I shouldn't be. (Negative life consequences) & 22 & 410 & 0.46 & 1.45 & 1.14 \\
\hline I find it difficult to switch off my mobile phone. (Withdrawal) & 13 & 411 & 0.36 & 2.56 & 2.58 \\
\hline I have been told that I spend too much time on my mobile phone. (Loss of control) & 24 & 410 & 0.47 & 2.86 & 2.68 \\
\hline I have received mobile phone bills I could not afford to pay. (Negative life consequences) & 7 & 411 & 0.33 & 1.37 & 1.40 \\
\hline
\end{tabular}


Table 6: Replication of the principal component analysis with the follow-up data: Factor loadings of the 27 items of the original Mobile Phone Problem Use Scale (MPPUS-27) on each factor after factor rotation. Item numbers relate to the MPPUS-27 questionnaire displayed in Table 1. The chosen items for the short version Mobile Phone Problem Use Scale-10 (MPPUS-10) are marked in light grey. The factor loadings of the chosen items for the particular factor are marked in bold.

\begin{tabular}{l|c|c|c|c|c}
\hline Factor & Loss of Control & Withdrawal & $\begin{array}{c}\text { Negative Life } \\
\text { Consequences }\end{array}$ & Craving & $\begin{array}{c}\text { Peer } \\
\text { Dependence }\end{array}$ \\
\hline Item & & & & & \\
\hline Item 1 & 0.14 & 0.23 & -0.08 & 0.12 & -0.06 \\
Item 2 & 0.06 & 0.04 & -0.02 & 0.51 & -0.02 \\
Item 3 & 0.30 & 0.06 & -0.03 & 0.07 & -0.01 \\
Item 4 & 0.17 & 0.07 & -0.37 & -0.12 & 0.03 \\
Item 5 & -0.01 & -0.09 & 0.31 & 0.33 & -0.06 \\
Item 6 & 0.16 & 0.10 & 0.16 & 0.00 & -0.06 \\
Item 7 & 0.00 & -0.01 & 0.32 & 0.03 & 0.08 \\
Item 8 & -0.07 & 0.42 & 0.03 & -0.03 & 0.10 \\
Item 9 & -0.02 & 0.20 & 0.13 & 0.19 & -0.06 \\
Item 10 & 0.18 & 0.13 & -0.10 & 0.09 & -0.21 \\
Item 11 & 0.05 & -0.05 & -0.03 & 0.56 & 0.08 \\
Item 12 & 0.22 & 0.14 & 0.04 & 0.04 & -0.20 \\
Item 13 & 0.13 & 0.36 & -0.02 & -0.14 & -0.04 \\
Item 14 & 0.00 & 0.47 & -0.12 & -0.02 & -0.05 \\
Item 15 & -0.09 & 0.06 & 0.40 & 0.00 & 0.03 \\
Item 16 & $\mathbf{0 . 4 8}$ & -0.13 & 0.06 & -0.21 & 0.03 \\
Item 17 & 0.14 & -0.03 & -0.12 & 0.14 & 0.53 \\
Item 18 & 0.21 & 0.02 & 0.23 & -0.01 & -0.11 \\
Item 19 & 0.06 & 0.02 & 0.39 & -0.08 & -0.04 \\
Item 20 & $\mathbf{0 . 3 1}$ & -0.01 & -0.03 & 0.19 & -0.01 \\
Item 21 & 0.34 & -0.03 & -0.04 & 0.06 & 0.08 \\
Item 22 & 0.09 & -0.05 & 0.37 & -0.05 & 0.04 \\
Item 23 & -0.07 & 0.37 & 0.19 & -0.11 & -0.02 \\
Item 24 & $\mathbf{0 . 4 3}$ & -0.06 & 0.05 & -0.11 & 0.04 \\
Item 25 & 0.07 & 0.05 & 0.16 & -0.24 & 0.41 \\
Item 26 & -0.03 & 0.10 & 0.02 & 0.06 & 0.63 \\
Item 27 & -0.05 & 0.36 & -0.01 & 0.14 & 0.09 \\
\hline
\end{tabular}


Figure 1: Correlation of the original 27-item Mobile Phone Problem Use Scale (MPPUS-27) score and the shortened 10-item Mobile Phone Problem Use Scale (MPPUS-10) score.

Pearson's correlation was $\mathrm{r} 0.95, \mathrm{p}<0.001$. Each dot displays a single participants MPPUS27 score on the $\mathrm{x}$-axis (range from 27 -270) and the corresponding MPPUS-10 score on the $\mathrm{y}$-axis (range from $10-100$ units).

Figure 1

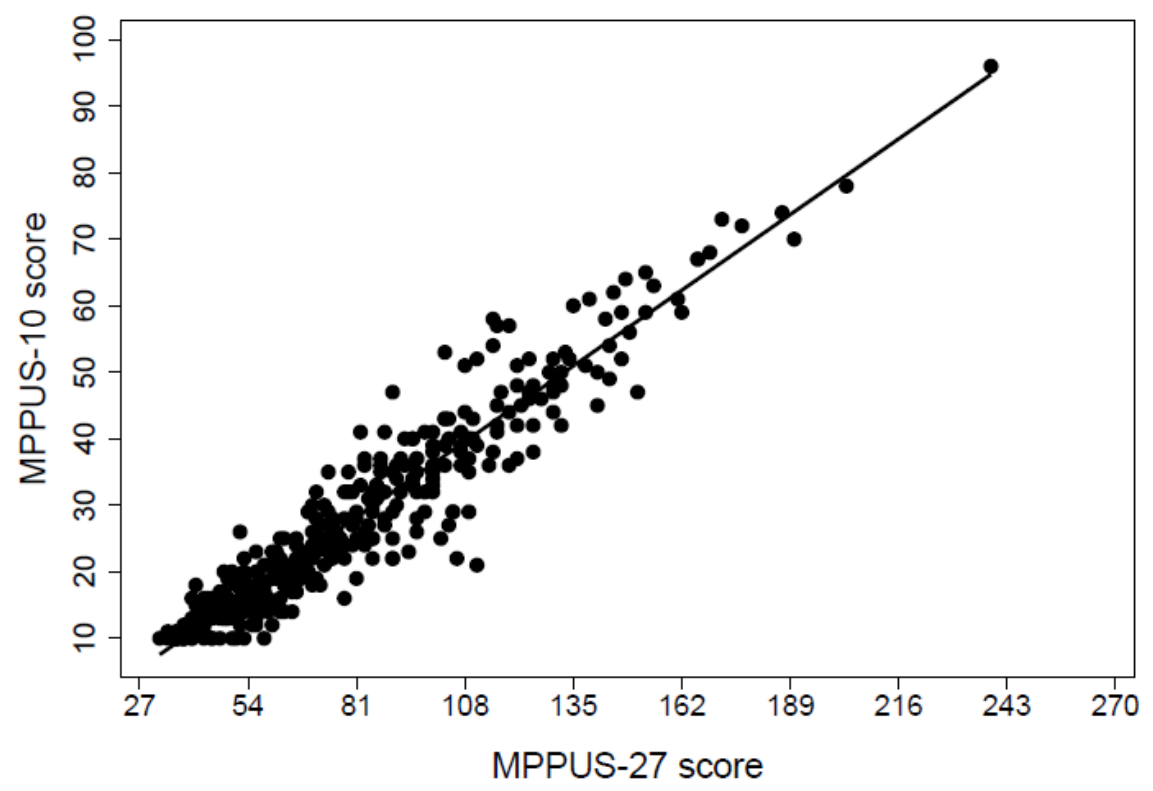

